\title{
Evaluation of Postoperative Complications after Surgical Removal of Impacted Lower Wisdom Teeth: a Prospective Study
}

Labeed Sami Hasan

B.D.S ,F.I.C.Ms , Senior lecturer - Oral and Maxillofacial Surgery Department/Tikrit University

\begin{abstract}
The removal of third molars is the most common procedure in oral surgery. It may be associated with minor complications such as pain, dry socket, infection, and major complications such as sensory disturbances and iatrogenic damage to the $2^{\text {nd }}$ molar or mandibular fractures.

Aim: The aim of this study was to evaluate the incidence of various complications, including pain, alveolitis, infection and damage to the inferior alveolar and lingual nerve that may occur during or after surgical removal of impacted mandibular third molars.
\end{abstract}

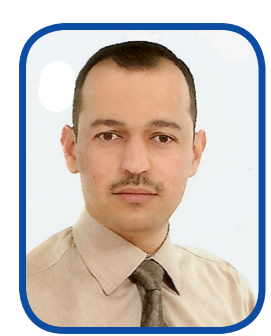

Materials and methods: This prospective study took place between March $1^{\text {st }}, 2013$ and January $29^{\text {th }}, 2014$ and it was done by the author. The sample consisted of 152 patients ( 90 males and 62 females with an age range of $20-45$ years). The patients underwent surgical removal of a completely or partially impacted lower wisdom tooth. All impacted third molars in the study were asymptomatic at the time of surgery. A standardized case sheet was filled for each patient and the patients were informed to register the pain and any other complications in these sheets.

Results: The overall complication rate was 35 patients (23.02\%). Twenty-three (15\%) patients developed moderate to severe pain, immediately after the operation lasting till the $3^{\text {rd }}$ or $4^{\text {th }}$ day postoperatively. Five patients $(3.42 \%)$ developed localized osteitis, four patients (2.73\%) developed postoperative oozing that lasted for 5 days, and three cases (1.97\%) developed postoperative infection. None of the patients developed postoperative lingual nerve or inferior alveolar nerve dysfunction.

Conclusion: Postoperative pain is the main complication after surgical removal of impacted lower wisdom teeth and alveolar osteitis is the second most important complication. Inferior alveolar nerve, lingual nerve damage and bleeding are very rare complications. The complications can be minimized by careful surgical extraction, postoperative medication and following postoperative instructions.

\section{KEYWORDS:}

Complications, surgical extraction, impaction, lower wisdom tooth

\section{CITE THIS ARTCLE:}

Hasan L.Evaluation of Postoperative Complications after Surgical Removal of Impacted Lower Wisdom Teeth: a Prospective Study. Iraqi Dent. J. 2015; 37(2):62-68. http://www.iraqidentaljournal.com

$$
\text { تقييم المضاعفات الصحية المصاحبة لعملية رفع الرحى الثالثة السفلية ”اسنان العقل“، : دراسة استطلاعية }
$$

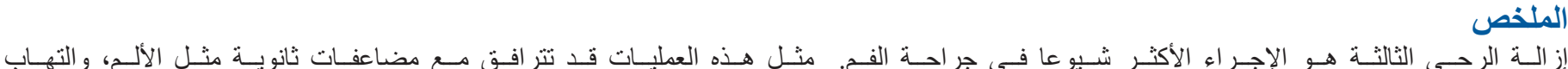

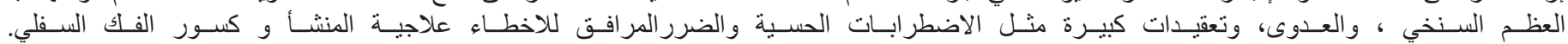

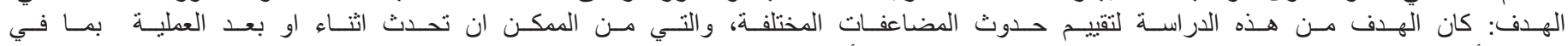

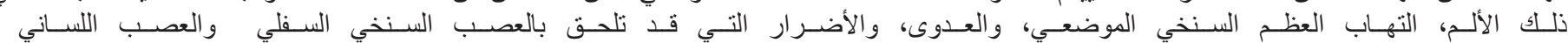

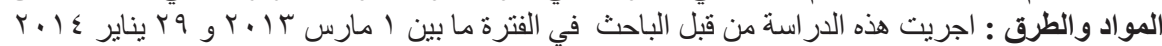

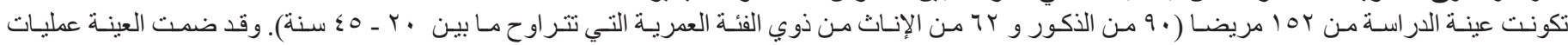

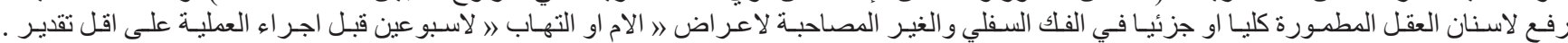

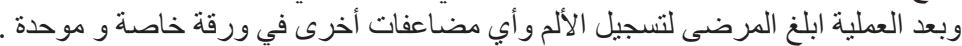

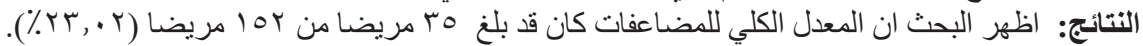

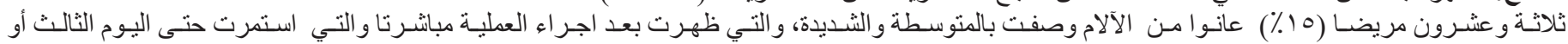

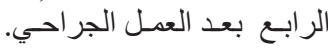

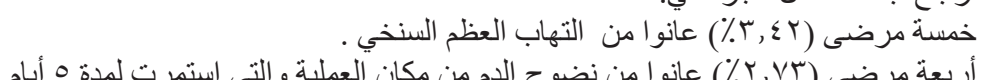

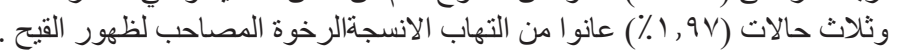

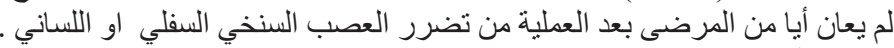

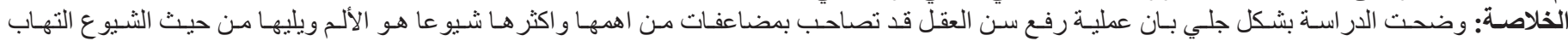

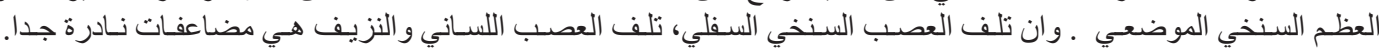

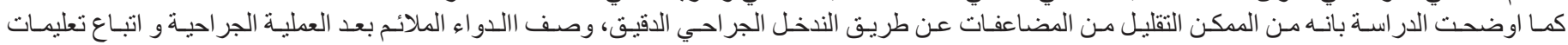
مـا بعد الجر احسة.

\section{INTRODUCTION}

The third mandibular molars are the most frequently impacted teeth in the human body ${ }^{(1)}$. Impaction can be defined as the tooth that fails to

erupt into a proper, functional position in the dental arch within the expected time ${ }^{(2)}$. Retention of the impacted teeth may be associated with complications, 
including neoplasm, cysts, fracture of the mandible and injury to the adjacent teeth usually through pathological root resorption or development of periodontitis, etc. ${ }^{(3)}$.

Studies have shown that patients with retained impacted third molars are significantly more susceptible to mandibular angle fracture (1, 4); therefore, many oral surgeons in America and Europe (5) consider prophylactic extraction of impacted teeth the ideal approach.

Many classifications have been suggested in order to predict the difficulty, postoperative complications and the treatment plan. Pell and Gregory ${ }^{(6)}$ classified the depth of the impaction into two categories.

The first category indicates the actual level or depth of the impacted lower $3^{\text {rd }}$ molar and as follows :

\section{Level A}

The impacted tooth occlusal plane is at the same level as the second molar occlusal plane.

\section{Level B}

The impacted tooth occlusal plane is located between the occlusal plane and the cervical line of the second molar.

\section{Level C}

The impacted tooth occlusal plane is located below the cervical line of the second molar.
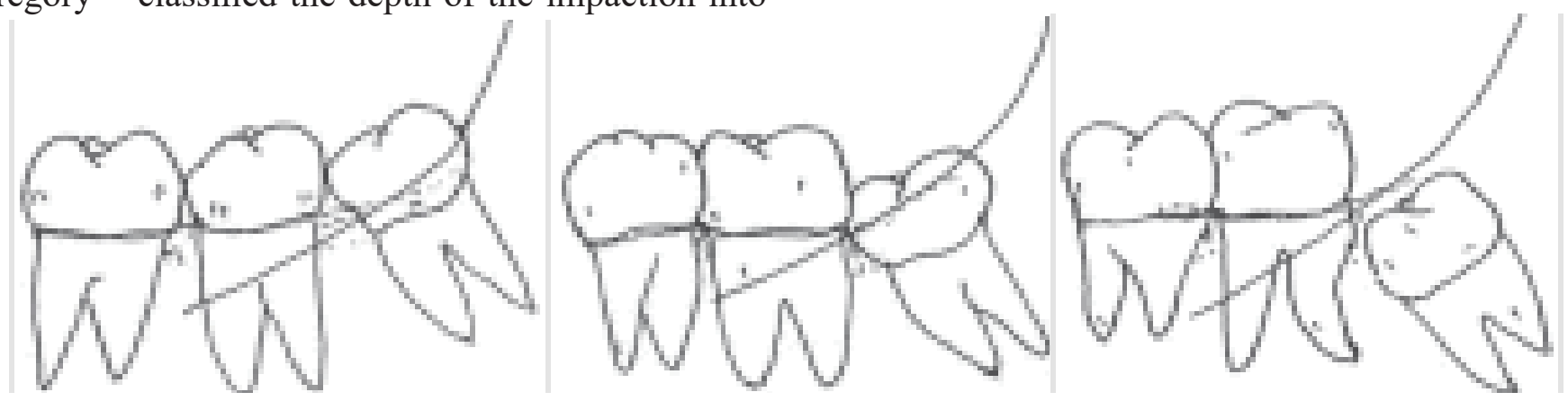

Fig 1 :Demonstrate the level of impaction according to pell and Gregory classification system ${ }^{(6)}$

Winter 7)() suggested a classification of the of the impacted tooth on the long axis of the second angulation of the third molar based on the relationship

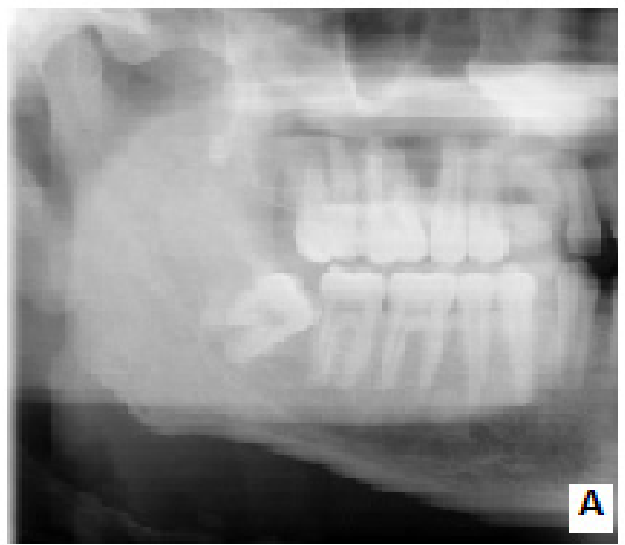
molar
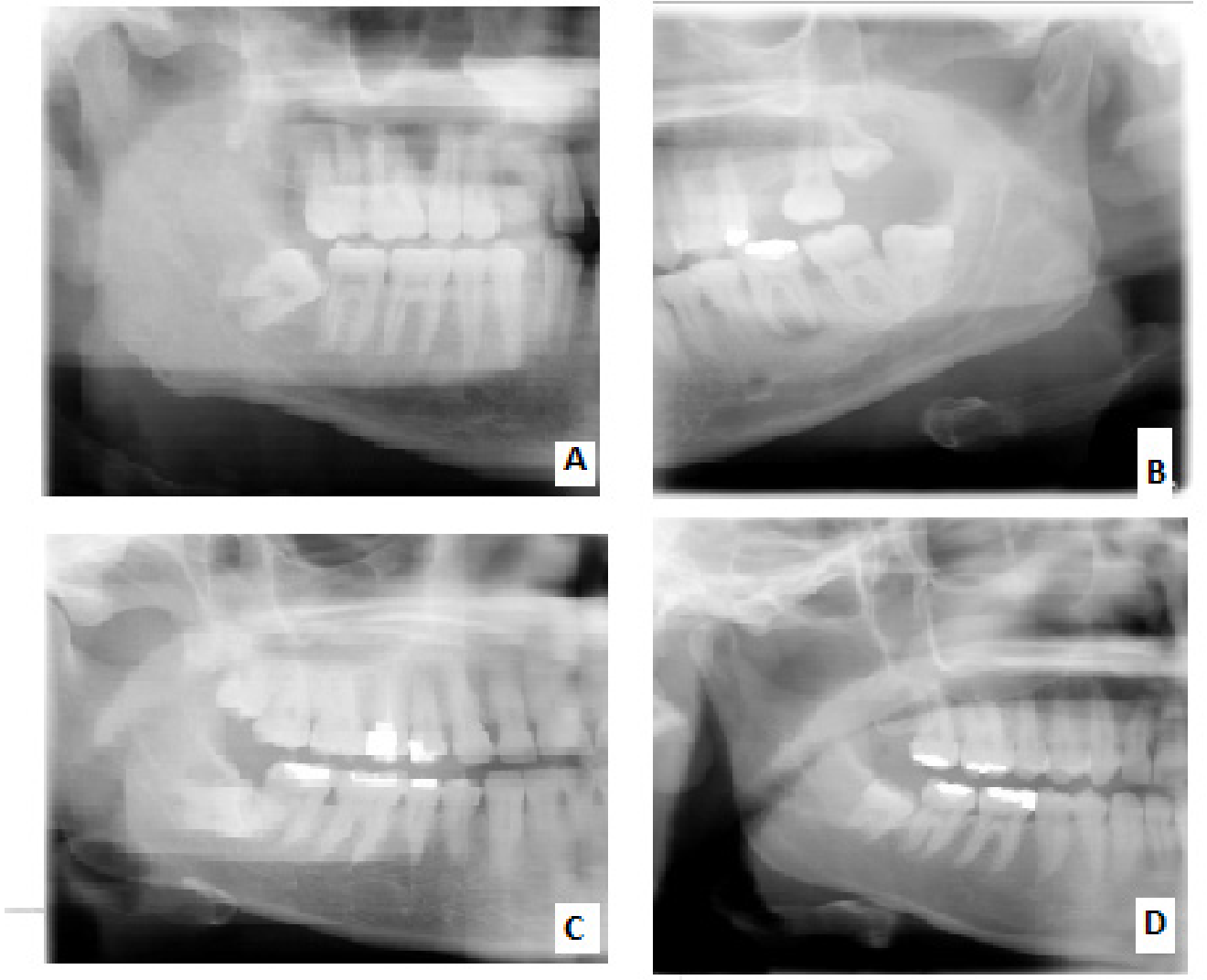

Fig: 2 demonstrate lower $3^{\text {rd }}$ molar angulation . A- mesioangular impaction, B- distoangular impaction ,C-Horizontal impaction, C-vertical impaction

The extraction of a wisdom tooth is one of the most common procedures performed in oral surgery units. The procedure is associated with a low complication

rate and most of them are minor. These complications include pain, dry socket, infection, hemorrhage and nerve damage. Less common complications include 
iatrogenic mandibular fractures, iatrogenic damage to the adjacent second molar and severe trismus. ${ }^{8}$,

Hemorrhage during or after surgery and paresthesia of the inferior dental nerve and lingual nerve are relatively rare. $(9,10)$

Pain is a subjective unpleasant emotional experience triggered by noxious stimuli that may or may not be associated with actual tissue damages; therefore, its measurement is difficult. However, some authors ${ }^{(11,12)}$ used pain measurement scales like four-point scale and visual analogue scale (VAS).

Dry socket is postoperative pain in and around the extraction site, which increases in severity at any time between 1 and 3 days after the extraction accompanied by a partially or totally disintegrated blood clot within the alveolar socket with or without halitosis ${ }^{(13)}$. The specific aim of this investigation was to identify the types and frequency of complications after mandibular $3^{\text {rd }}$ molar extractions and the relation with the level and angulation of impaction.

\section{MATERIALS AND METHODS}

This prospective clinical study took place between March $1^{\text {st }}, 2013$ and January $29^{\text {th }}, 2014$ and the researcher did it at the Private Dental practice and Oral and Maxillofacial Surgery Department College of Dentistry, Tikrit University. The sample included 152 patients (90females and 62 males with an age range of $20-45$ years) who underwent surgical removal of completely or partially impacted lower $3^{\text {rd }}$ molars. The patients were healthy and their impacted third molars were asymptomatic at the time of surgery.

A standardized case sheet was filled for each patient; with a special paper designed for recording pain according to Visual Analog Scale (VAS), a scale starts from 0 to 10 grades in which 0 represents no pain, while 10 represents the worst possible pain.

For each patient, a panoramic ORTHOPANTOGRAM (OPG) image was taken preoperatively to determine the status of wisdom teeth, preoperative prophylactic antibiotic was given (Augmentin $1 \mathrm{gm}$ ) twice daily, the first tablet was given one hour before the procedures and followed by a daily regimen of antibiotic with Non-Steroidal Anti-Inflammatory Drug (NSAID) for 5 days postoperatively. Two carpules of local anesthesia were given (lidocaine 2\%, adrenaline 1:00000), a standard two sided flap on the buccal aspect was done, avoiding reflection of lingual mucoperiosteum, bone removal was done under copious irrigation with normal saline and povidone iodine, tooth sectioning was done when indicated (mesio-angular impaction or horizontal impaction).
After the extraction, the bony irregularity was smoothed or removed with emphasis on primary closure of the operation site during suturing with $3 / 0$ black silk suture, with the application of chlorexidine gel on the suture line .

The patients were instructed to rinse their mouth with chlohexidine twice a day, to refrain from smoking during the postoperative period, to register the pain and any other complications in standard paper, and they were recalled after 7 days for suture removal.

\section{The inclusion criteria are:}

- All patients were medically fit with no systemic disease.

- One impacted tooth was extracted at each visit.

- For all procedures 2 carpules local anesthesia were used.

- All molars were asymptomatic at the time of surgery.

- For all patients two-sided flap was done .

- The irrigation was done with normal saline and povidone iodine.

\section{The exclusion criteria are:}

- Lingual flap reflection or lingual split technique.

- Any patient with recent infection or pericoronitis in the last 2 weeks.

- Pregnant or lactating patients.

- Cases of ankylosis.

- Cases with concomitant extraction of lower seven.

- Operation that irrigated with other than normal saline and povidone iodine.

- Any flap other than two-sided flap.

- Pathological condition.

Impaction Case Sheet
Patient's Name:
Patient Age:
Date:
Sex:
Address (including telephone number):
Chief Complaint:
Medical History:

\section{Classification of Impaction}

A-Pre-Operative Classification (Pell-Gregory):

Level A:

Level B: ( )

Level $\mathrm{C}$ :

B-Winter classification

1 - Vertical

2- Mesioangular

3- Distoangular

4- Horizontal

Remarks: 


\section{RESULTS}

The overall complication rate was encountered in thirty five " 35 " patients $(23.02 \%), 19$ females $(21.5 \%)$ and 16 males $(25.8 \%)$, as seen in Table 1.

Twenty-three patients (15\%), 13 females and 10 males developed pain which is moderate to severe and ranging (5-8)with the mean of 6.2, .the pain started after the operation and reach the peak in the $1^{\text {st }}$ post operative day then start to decline after and disappear by $4^{\text {th }}$ and $5^{\text {th }}$ post operative day.

Five patients (3.42\%) (3 females and 2 males) developed localized osteitis according to

definition of dry socket required active local measure with normal saline irrigation and insertion

Table1 : Post operative complications according to gender of alvogyl in the socket .

Four patients $(2.73 \%) \quad$ ( 2 females and 2 males) developed postoperative bleeding that lasted for 5 days postoperatively. Three $3(1.97 \%)$ patients (1 female and 2 male) developed post operative infection. None developed postoperative lingual or inferior alveolar nerve dysfunction.

The highest complication was seen in mesioangular impaction (9.86\%), while the lowest was seen in the distoangular impaction (about $0.65 \%$ ) .as seen clearly in Table 2 .

The highest complication in the present study was seen in level C impaction (11.18\%) and the lowest for level A impaction (3.28\%), as seen clearly in table 2.

\begin{tabular}{|c|c|c|c|c|}
\hline Complications & Female number & Male number & N\&\% out of sample & \% out of complications \\
\hline Over all complication & $19(21.5 \%)$ & $16(25.8 \%)$ & $35(23.02 \%)$ & - \\
\hline Pain & $13(14.44 \%)$ & $10(16.1 \%$ & $23(15 \%)$ & $65 \%$ \\
\hline Localized osteitis & $3(3.33 \%)$ & $2(3.22 \%)$ & $5(3.42 \%)$ & $14 \%$ \\
\hline Post operative bleeding & $2(2.22 \%)$ & $2(3.22 \%)$ & $4(2.73 \%)$ & $11.42 \%$ \\
\hline Post operative infection & $1(1.11 \%)$ & $2(3.22 \%)$ & $3(1.97 \%)$ & $8.57 \%$ \\
\hline IAN\&LN damage & 0 & 0 & 0 & 0 \\
\hline
\end{tabular}

Table 2: Number and percentage of surgically extracted mandibular wisdom molars according to type of angulation and postoperative complications

\begin{tabular}{|l|c|c|c|c|}
\multicolumn{1}{c|}{ Type of impaction } & Horizontal & Vertical & Mesioangular & Distoangular \\
\hline Incidence of impaction & $\mathrm{N}=19(13 \%)$ & $\mathrm{N}=66(45 \%)$ & $\mathrm{N}=51(34.9 \%)$ & $\mathrm{N}=10(6.8 \%)$ \\
\hline Dry socket & $1(5.26 \%)$ & $2(3.03 \%)$ & $2(3.9 \%)$ & 0 \\
\hline Infection & $1(5.27 \%)$ & 0 & $2(3.9 \%)$ & 0 \\
\hline Pain & $5(26.3)$ & $7(10.6 \%)$ & 10 & $1(10 \%)$ \\
\hline Bleeding & $1(5.2)$ & $2(3.03 \%)$ & $1(1.9 \%)$ & 0 \\
\hline Nerve injury & 0 & 0 & 0 & 0 \\
\hline Complications out of angulation & $8(42.1 \%)$ & $11(16.66 \%)$ & $15(29.4 \%)$ & $1(10 \%)$ \\
\hline Complications out of sample & $5.26 \%$ & $7.23 \%$ & $9.86 \%$ & $0.65 \%$ \\
\hline
\end{tabular}

Table 3 :Post operative complications according to impacted lower wisdom tooth level
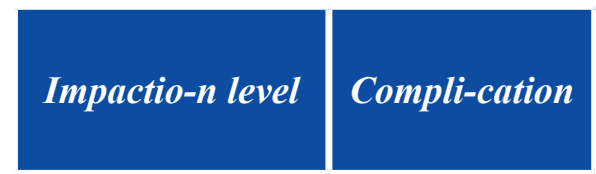

Level A

Level B

Level C

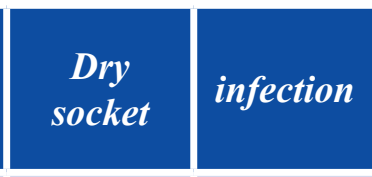

5
12
17
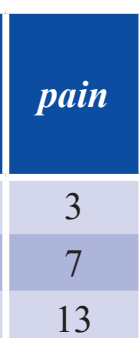
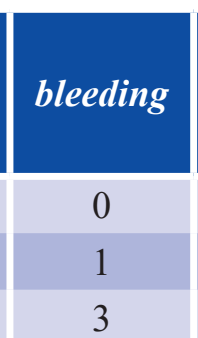

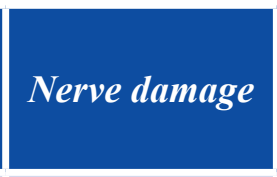

0
0
0

\section{Complication \\ level/sample}

$3.28 \%$

$7.89 \%$

$11.18 \%$

\section{DISCUSSION}

Several studies have been written concerning the appropriate management of impacted wisdom teeth, with conflicting reports of its efficacy and complications. Retention of the impacted teeth may be associated with complications that may include neoplasm, cysts, fracture of mandible and injury to adjacent teeth etc ${ }^{(3)}$. Therefore, many surgeons in America and Europe (5) have advocated prophylactic surgical removal of impacted teeth. 
Several articles were written concerning surgical removal of impacted lower $3^{\text {rd }}$ molars all around the world trying to identify the risk factors related to the procedures and the methods that minimize the complications.

Factors that may be correlated with these complications, such as:

- Factors that cannot be changed or modified such as gender, age, angulation and the level of impaction. $(14,15,16,17)$

- Factors can be eliminated or modified such as alcohol consumption, smoking, oral contraceptives, preexisting inflammatory condition, oral hygiene, antibiotics, corticosteroids, type of the flap and its extension, bone removal, and the surgeon experience. In the current study the researcher tried to reduce or eliminate this group of factors $(9,18,19,20,21,22,23)$

- Postoperative pain, swelling, dry socket and trismus are acute reversible short-term inflammatory complications of surgical removal of the impacted mandibular third molars ${ }^{(24) .}$ Every effort directed toward minimizing or prevention of these short term complications (2)

I emphasizes that trauma is inevitable during surgery which leads to delayed wound healing by compressing bony lining of the socket, thus compromising vascular penetration and the perfusion of the surgical site and this is in agreement with A. E. Swanson and Caso A et al ${ }^{(25,26)}$,Therefore complications are inevitable, the surgeon work on the ways to minimize the complications

The VAS, has been used in the current study for evaluation of pain, which considered as a sensitive and reliable method for recording pain. As demonstrated clearly by Berge . (27.28).

The overall complications rate was $23.02 \%$, and this is in consistence with incidence reported by many studies in which the overall complications range (4.4 to $30.9 \%)^{(29,30)}$ and most of the complications are mild and temporary .

The overall complication rate for female was $21.5 \%$, while for male $8 \%$. This difference can be attributed in part to that, female follow the postoperative instruction while most of male reported to be careless with smoking after the operation that revealed clearly after the questioner and females on contraceptive were excluded from the study.

Twenty-three patients $(15 \%)$ developed pain and this is in agreement with Rosfaima Othman et al ${ }^{(31)}$. This pain reflect inflammatory response to the trauma with release of pain mediator and its magnitude correspond with amount of trauma and duration of operation. In this study as it is demonstrated in table 1 and 2 the pain incidence in more common with mesioangular impaction and with impaction in Level c , in both the amount of bone removal "surgical trauma " and the difficulty of extraction is the greatest and this in accordance with many studies $(16,17,19,26,32,33)$

The intensity of postoperative pain in the current study reached the peak on the first postoperative day, and this is in agreement with finding of a previous studies. The pain then started to reduce gradually. $(34,35)$

Alveolar osteitis characterized by a severe throbbing pain that usually begins 3 to 5 days postoperatively ${ }^{(36)}$ By this time, most of the pain and swelling associated with surgical trauma should disappear, and residual radiating pain to the ear is a common complaint in patients with alveolar osteitis

Trauma is the major cause that lead to delayed wound healing through compromising vascularity of the surgical site ${ }^{(25)}$ The greater the trauma and difficulty in extraction the greater risk of developing alveolar osteitis $(19,26,32,33)$ and this can be seen clearly in the current study as highest complications are associated with level $\mathrm{C}$ impaction where that amount of trauma is the greatest. Blondeau and Daniel; found that alveolitis occur in about $(3.6 \%)^{(37)}$

Others reported incidences vary from 1 to $30 \%$ ( 30). all these studies are in agreement with this study in which the author reported only (3.42\%) incidence of dry socket .

The complication of dry socket value was low when compared to previous data collected from other studies. This may be attributed in part to the following: - The differences in diagnostic criteria and the methods of assessment (13). Several authors have agreed that pain and empty alveolus are found in all patients with alveolar osteitis and that what has been found in this study ${ }^{(25,38)}$.

- The most important variable listed in the literatures been fixed which is multiple operators in the present research the author eliminate this variable as well as the factor of in experienced dentist, in this point the author agree with François Blondeau (37)

- Avoidance of lingual flap reflection with the aim to reduce the trauma and preserve the blood supply to extraction site .The rate of alveolar osteitis is significantly affected by lingual flap retraction ${ }^{(15,37)}$

- Every effort was done to get primary closure of the socket site.

- Copious irrigation with normal saline and povidone iodine may be of value 
- Suture line coverage with chlohexidne ointment in combination with mouth washes with chlohexidine was prescribed. The effect of chlorhexidine in reduction of alveolar osteitis is in agreement with Caso et al ${ }^{(39)}$.

- Female on oral contraceptives were excluded from this study, this could explain the finding that gender had no relation to the incidence of alveolar osteitis

The frequency of clinically significant bleeding was $2.73 \%$ and this is in agreement with reported ranges of $0.2 \%$ to $5.8 \%{ }^{(41)}$

Postoperative infection was seen in $1.97 \%$ of sample and diagnosed by intense pain, lymph adenopathy, fever and/or purulent discharge , Its was within the range that reported in literature which lies between 1.0 (Hochwald et al $\left({ }^{42}\right)$ ) and 12.6 (Nordenram et al ${ }^{(43)}$.

No case of lingual nerve and inferior alveolar nerve injury had been seen in this study, while the inferior alveolar nerve and lingual nerve injury level reported in the literature ranges from $0 \%$ to $23 \%$. $^{(44,45)}$.

In the current study due to avoidance of reflection of lingual mucoperiostium and the distance between the impacted $3^{\text {rd }}$ molar and inferior dental canal was more than $1.5 \mathrm{~mm}$ there for I avoid injury to lingual and inferior alveolar nerve, respectively.

\section{CONCLUSION}

Postoperative pain is the main minor complication; alveolar osteitis is the second most important complication, while inferior alveolar nerve and lingual nerve damage are very rare complications. Perioperative medications, both topical and systemic, careful surgical extraction by trained surgeons, and postoperative instructions proved to have impact on prognosis through minimizing the complications associated with surgery.

\section{REFERENCES}

1. Dimitroulis G . A Synopsis of Minor Oral Surgery. Oxford university press: 1997 . Chapter 6, pp 48-57.

2. Obimakinde OS. Impacted mandibular third molar surgery; an overview. Dentiscope, 2009; volume 16, January.

3. Ma'aita J and Alwrikat A. Is the mandibular third molar a risk factor for mandibular angle fracture? Oral Surg Oral Med Oral Pathol Oral Radiol Endod, 2000;89(2): 143-146.

4. Fuselier JC, Ellis EE 3rd and Dodson TB .Do mandibular third molars alter the risk of anglefracture? J Oral Maxillofac Surg, 2002; 60(5): 514-518.

5. Sağlam AA, Tüzüm MS. Clinical and radiologic investigation of the incidence, complications, and suitable removal times for fully impacted teeth in the Turkish population. Quintessence Int, 2003 ;34(1): 53-59.

6. Pell GJ, Gregory BT. Impacted mandibular third molars: Classification and modified techniques for removal. Dent
Digest. 1933;39:330-8.

7. Sham Kishor Kanneppady, Balamanikandasrinivasan, Ramesh Kumaresan, and Santosh B. SakriA . comparative study on radiographic analysis of impacted third molars among three ethnic groups of patients attending AIMST Dental Institute, Malaysia .Dent Res J (Isfahan). 2013 May-Jun; 10(3): 353-358. PMCID: PMC3760359)

8. Yitzhak Woldenberg et al, Iatrogenic mandibular fracture associated with third molar removal. Can it be prevented? Med Oral Patol Oral Cir Bucal 2007;12:E70-2.

9. Sisk AL, Hammer WB, Shelton DW, Joy ED Jr. Complications following removal of impacted third molars: the role of the experience of the surgeon. J Oral Maxillofac Surg 1986; 44(11):855-9.

10. Lopes V, Mumenya R, Feinmann C, Harris M. Third molar surgery: an audit of the indications for surgery, postoperative complaints and patient satisfaction. Br J Oral Maxillofac Surg 1995; 33(1):33-5.

11. Jose Rodrigues Laureano Filho, Emanuel Dias de Oliveira e Silva, Igor Batista Camargo, and Fabiana MV Gouveia. The influence of cryotherapy on reduction of swelling, pain and trismus after third molar extraction. J Am Dent Assoc, Vol 136, No 6,774-778.

12. AB Barroso, V Lima, GC Guzzo, RA Moraes, MC Vasconcellos, MM Bezerra, FAL Viana, RCR Bezerra, GSM Santana, FA Frota-Bezerra, MO Moraes and MEA Moraes. Efficacy and safety of combined piroxicam, dexamethasone, orphenadrine, and cyanocobalamin treatment in mandibular molar surgery. Braz J Med Biol Res, September 2006, Volume 39(9) 1241-1247.

13. Blum IR. Contemporary views on dry socket (alveolar osteitis): a clinical appraisal of standardization, aetiopathogenesis and management: a critical review. Int J Oral Maxillofac Surg 2002;31:309-17

14. Bello S. A., Adeyemo W., Bamgbose B., Obi E., Adeyinka A. A . Effect of age, impaction types and operative time on inflammatory tissue reactions following lower third molar surgery. Head \& Face Medicine 2011, 7:8;3.

15. Baqain Z. H., , Abu Karaky A., Sawair F., , Khaisat A. , Rajab L., Frequency Estimates and Risk Factors for Postoperative Morbidity After Third RemovalMolar Removal: A Prospective Cohort Study J Oral MaxillofacSurg 2008;66:2276-2283.

16. Yuasa H, Kawai T, Sugiua M. Classification of surgical difficulty in extracting impacted third molars. Br J Oral Maxillofac Surg 2002; 40:26-31.

17. Chi $\mathrm{H}$ et al . Types, Frequencies, and Risk Factors for complications After Third Molar Extraction . J Oral Maxillofac Surg, 2003 ;61:1379-1389.

18. Benediktsdottir IS, Wenzel A, Petersen JK, et al: Mandibular third molar removal: Risk indicators for extended operation time, postoperative pain, and complications. Oral Surg Oral Med Oral Pathol Oral Radiol Endod ,2004; 97:438.

19. Jerjes W, El-Maaytah M, Swinson B, et al: Experience versus complication rate in third molar surgery.2006; Head Face Med 25:14.

20. Renton T, Smeeton N, McGurk M: Factors predictive of difficulty of mandibular third molar surgery. 2001; Br Dent J 190:607.

21. Nusair YM, Younis MH: Prevalence, clinical picture, and risk factors of alveolar osteitis in a Jordanian dental teaching center.2007 ;J Contemp Dent Pract 8:53.

22. Rubio-Palau J, et al, Effect of intra-alveolar placement of 
$0.2 \%$ chlorhexidine bioadhesive gel on the incidence of alveolar osteitis following the extraction of mandibular third molars. A double-blind randomized clinical trial. Med Oral Patol Oral Cir Bucal. 2015 Jan 1;20(1):e117-22.

23. Monaco G, Staffolani C, Gatto MR, et al: Antibiotic therapy in impacted third molar surgery. Eur J Oral Sci ,1999;107:437.

24. Victoria AM. Relation of patient and surgical variables to postoperative pain and inflammation in the extraction of third molars. Medicina Oral ,2002; 7: 360-369.

25. Birn H: Etiology and pathogenesis of fibrinolytic alveolitis ("alveolar osteitis"). Int Oral Surg ,1973; 2:215.

26. De Boer MP, Raghoebar GM, Stegenga B, et al: Complications after mandibular third molar extraction. Quintessence Int , 1995; 26:779.

27. David D, Marvin P, Chinnis RJ. Comparison of primary and secondary closure techniques after removal of impacted mandibular third molars. J Oral Maxillofac Surg. 1982;11:631-634. [PubMed].

28. Berge TI. Visual analogue scale assessment of postoperative swelling: a study of clinical inflammatory variables subsequent to third-molar surgery. Acta Odontol Scand. 1988;46:233-240. doi: 10.3109/00016358809004772. [PubMed] [Cross Ref].

29. Bui CH, Seldin EB, DodsonTB .Type, frequencies and risk factors doe complications after third molar extraction .journal of oral and maxillofacial surgery, 2003;61(12):1379-8.

30. Bouloux GF,Steed MB,Periaccante VJ .Complications of third molar surgery .oral and maxillofacial surgery clinics of north America 2007;19(1):117.

31. Rosfaima Othman@Jaffar, Mon Mon Tin-Oo. Impacted mandibular third molars among patients attending Hospital Universiti Sains Malaysia, Archives of Orofacial Sciences (2009); 4(1): 7-12.

32. Chuang SK, Perrott DH, Susarla SM, er al: Age as a risk factor for third molar surgery complications. J Oral Maxillofac Surg ,2007;65:1685.

33. Turner PS: A clinical study of "alveolar osteitis." ,1982; Int J Oral Surg 11:226.

34. White RP et al : Recovery after third molar surgery: clinical and healthrelated quality of life outcomes. J Oral Maxillofac Surg 2003, 61:535-544.

35. Babatunde O. B.et al . Effects of co-administered dexamethasone and diclofenacpotassium on pain, swelling and trismus following third molarsurgery Head \& Face Medicine 2005, 1:11

36. Larsen PE. Alveolar osteitis after surgical removal of impacted mandibular third molars: identification of the patient at risk. Oral Surg Oral Med Oral Pathol, 1992; 73:393-7.

37. Blondeau F and Daniel NG. Extraction of impacted mandibular third molars: postoperative complications and their risk factors. J Can Dent Assoc, may 2007; 73(4): 325325.

38. A. E. Swanson, "Prevention of dry socket: an overview," Oral Surgery Oral Medicine and Oral Pathology, 1990 ;vol. 70, no. 2, pp.131-136.

39. Caso A,Hung L-K, Beirne OR . Prevention of alveolar osteitis with chlorhexidine :A meta analytic review. Oral surgery oral Med Oral radiol Endod 2005;99:155-159.

40. Chiapasco M, De Cicco L, Marrone G: Side effects and complications associated with third molar surgery. Oral
Surg Oral Med Oral Pathol1993 ; 76:412.

41. Muhonen A, Iventa" I, Ylipaavalniemi P: Factors predisposing to postoperative complications related to wisdom tooth surgery among university students.1997; J Am Coll Health 46:39.

42. Hochwald DA, Davies WH, Martinoff J. Modified distolingual splitting technique for removal of impacted mandibular third molars: incidence of postoperative sequelae. Oral Surg Oral Med Oral Pathol 1983; 56: 9-11.

43. Nordenram A, Sydnes G, Odegaard J. Neomycin-bacitracin cones in impacted third molar sockets. Int J Oral Surg 1973; 2: 279. I PubMed

44. Bataineh AB: Sensory nerve impairment following mandibular third molar surgery. J Oral Maxillofac Surg ,2001;59:1012.

45. Chye EP, Young IG, Osborne GA, et al: Outcomes after same day oral surgery: A review of 1,180 cases at a major teaching hospital. J Oral Maxillofac Surg,1993; 51:846. 